\title{
Effects of L-Propionylcarnitine on Ischemia Induced Myocardial Dysfunction in Men with Angina Pectoris
}

\author{
G. Louis Bartels, MD, Willem J. Remme, MD, PhD, Mike Pillay, PhD, \\ Dirk H. W. Schönfeld, MD, and Dick A. C. M. Kruijssen, MD
}

\begin{abstract}
To identify the effect of L-propionylcamitine (LPC) on ischemia, 31 fasting, untreated male patients with left coronary artery disease were studied during 2 identical pacing stress tests 45 minutes before (atrial pacing test I [APST I]) and 15 minutes after (APST II) administration of 15 $\mathrm{mg} / \mathrm{kg}$ of LPC or placebo. Hemodynamic, metabolic, and nuclear angiographic variables were studied before, during, and for $\mathbf{1 0}$ minutes after pacing. After LPC administration, arterial total camitine levels increased from $47 \pm 1.7$ $\mu \mathrm{mol} /$ itter (control) to $730 \pm 30 \mu \mathrm{mol} /$ liter. Hemodynamic and metabolic variables were comparable in LPC and placebo during APST I, and reproducible in placebo during both tests. Although LPC did not affect myocardial oxygen demand and supply, it diminished myocardial ischemia, indicated by a significant $12 \%$ and $50 \%$ reduction in ST-segment depression and loft ventricular end-diastolic pressure, respectively, during APST II. Moreover, during APST II, left ventricular ejection fraction increased by $18 \%$ ( $p$ <0.05 vs APST I). Furthermore, LPC improved recovery of myocardial function after pacing, with a reduction in the time to peak filling and a $21 \%$ increase in both peak ejection and filling rates 10 minutes after pacing (all p <0.05). Thus, LPC prevents ischemia-induced ventricular dysfunction, not by affecting the myocardial oxygen supply-demand ratio but as a result of its intrinsic metabolic actions, increasing pyruvate dehydrogenase activity and flux through the citric acid cycle. Because it is well tolerated, it may be a valuable altemative or addition to available antischemic therapy.
\end{abstract}

(Am J Cardiol 1994;74:125-130)

From the Sticares Cardiovascular Research Foundation, Zuiderziekenhuis, and Department of Nuclear Medicine of the Dr. Daniel den Hoed Cancer Centre, Rotterdam, The Netherlands. Manuscript received September 24, 1993; revised manuscript received December 12, 1993 , and accepted December 13

Address for reprints: W. J. Remme, MD, PhD, Sticares Cardiovascular Research Foundation, P.O. Box 52006, 3007 LA Rotterdam, The Netherlands.
$B$ ecause available anti-ischemic agents are often inadequate due to incomplete efficacy or adverse effects, there is a need for alternative pharmacologic strategies (e.g., metabolic anti-ischemic therapy). L-carnitine mediates mitochondrial fatty acid transport and regulates mitochondrial high-energy phosphate exchange through the activity of adenine nucleotide translocase. ${ }^{1,2}$ Moreover, it stimulates pyruvate dehydrogenase and improves the flux of pyruvate into the citric acid cycle. ${ }^{3}$ As the heart is unable to synthesize L-carnitine, it is critically dependent on external supply. ${ }^{4,5}$ During ischemia, total and free myocardial carnitine levels decrease ${ }^{6,7}$ In addition, acyl coenzyme A (CoA) accumulates and inhibits adenine nucleotide translocase and pyruvate dehydrogenase activity. Administration of L-carnitine may reverse this inhibition. ${ }^{1}$ In both animals and humans, anti-ischemic effects of L-carnitine have been reported. ${ }^{8-11}$ L-propionylcarnitine (LPC), a natural derivative of L-carnitine, may be more effective in this respect, because it is more rapidly accessible to the cardiocyte $^{12,13}$ and may increase the citric acid flux through newly formed propionyl-CoA. ${ }^{14}$ Indeed, animal models of ischemia-reperfusion indicate a protective effect of intravenous LPC. ${ }^{15,16}$ Because no human data are available, the present study evaluated the anti-ischemic effects of intravenous LPC in patients with coronary artery disease.

\section{METHODS}

Patients: After approval of the institutional ethical review board and informed consent, 31 normotensive male patients aged 46 to 73 years (mean 57) with angina pectoris and objective signs of exercise-induced ischemia were evaluated. Twenty patients had a documented myocardial infarction. Patients with unstable angina, arterial hypertension (systolic pressure $>220 \mathrm{~mm}$ $\mathrm{Hg}$, diastolic pressure $>100 \mathrm{~mm} \mathrm{Hg}$ ), symptoms or signs of congestive heart failure, conduction abnormalities, valvular heart disease, diabetes mellitus, and renal or hepatic dysfunction were excluded. Previous myocardial infarctions had to be at least 1 month old. All cardiac medication was withheld 24 to 72 hours before the investigation. Only short-acting nitroglycerin was allowed until 6 hours before the study. None of the patients received digitalis. To participate, patients had to have a diameter stenosis of $\geq 70 \%$ in either the left anterior descending artery, a diagonal branch, the proximal part of the left circumflex artery, or a proximal marginal branch. Nine patients had 1-vessel, 11 patients 2-vessel, and 11 patients 3-vessel disease. 
TABLE I Baseline Characteristics of Patients

\begin{tabular}{|lcc|}
\hline & L-Propionylcarnitine & Placebo \\
\hline Number of patients & 15 & 16 \\
Age (years) & $59 \pm 2$ & $58 \pm 2$ \\
Previous myocardial infarction & $13^{*}$ & 7 \\
Anterior & 6 & 3 \\
Inferior & 8 & 4 \\
Number of coronary arteries & & \\
narrowed $>70 \%$ in diameter & 6 & 3 \\
1 & 3 & 8 \\
2 & 6 & 5 \\
3 & & $62 \pm 5$ \\
Left ventricle & $73 \pm 6$ & $50 \pm 3$ \\
End-diastolic volume (ml/m²) & $43 \pm 4$ & \\
Ejection fraction (\%) & & \\
\hline${ }^{*} p<0.05$ L-propionylcarnitine versus placebo. & \\
Data are mean \pm SEM. & & \\
\hline
\end{tabular}

Instrumentation: Studies were conducted in the morning, without premedication and with the patient fasting. First, left and right coronary angiography was performed, using the Seldinger technique. If patients met the inclusion criteria, a no. 7Fr thermodilution flow and pacing catheter (Wilton Webster I aboratories) was advanced into the midportion of the coronary sinus through a brachial vein so that its position was stable and blood could be drawn easily. The absence of atrial reflux was confirmed by bolus injections of saline solution at room temperature in the right atrium. Next, a no. 7Fr triplelumen thermodilution catheter was positioned in a pulmonary artery through the right femoral vein and a no. 8Fr Sentron pigtail microtip manometer catheter advanced into the left ventricle through a no. 9Fr Desilet introducer system in the right femoral artery. The side arm of the latter was used to monitor arterial pressures. The position of the catheters was recorded on video and checked throughout the study.

Hemodynamic and electrocardiographic measurements: All fluid-filled catheters were calibrated using a zero reference level set at midchest. Pressures in the right atrium and in the femoral and pulmonary arteries were measured using Bentley transducers (BaxterBentley, Uden, The Netherlands). All pressures were recorded on paper at different paper speeds (i.e., at 10 , 25 , and $100 \mathrm{~mm} / \mathrm{s}$ ) using a Nihon Kohden cath lab system. In addition, pressure-derived contractility and relaxation indexes were determined on-line by a Mennen cath lab computer system. In a beat-to-beat analysis, this system averages 15 to 20 consecutive beats to level out respiratory variations. Coronary sinus blood flow was determined during a continuous 30-second infusion of $50 \mathrm{ml}$ of $5 \%$ glucose at room temperature. ${ }^{17}$ Electrocardiographic leads I, II, and $\mathrm{V}_{5}$ were continuously monitored. The ST-segment level was assessed with a calibrated magnifying lens in 5 consecutive beats 0.08 second after the J point at a paper speed of $100 \mathrm{~mm} / \mathrm{s}$.

Metabolic measurements: Blood sampling for metabolic determinations was performed simultaneously from the left ventricle and the coronary sinus. Oxygen saturation was determined with an OSM-80 oximeter (Waters Associates). For lactate, exactly $1 \mathrm{ml}$ was sampled in $2 \mathrm{ml}$ of ice cold $0.6 \mathrm{M}$ perchloric acid, and an- alyzed as previously reported. ${ }^{18}$ Blood samples $(1 \mathrm{ml})$ for hypoxanthine analysis were collected in precooled heparinized tubes containing $0.5 \mathrm{ml}$ of $40 \mu \mathrm{M}$ of dipyridamole and $0.5 \mathrm{ml}$ of $20 \mu \mathrm{M}$ of erythro-9-(2-hydroxy-3nonyl) adenine. Hypoxanthine was assayed by dual-column high-pressure liquid chromatography as reported. ${ }^{18}$ The standard deviation is $0.2 \mu \mathrm{M}$. For the analysis of free and total L-carnitine, $2 \mathrm{ml}$ of arterial blood was collected in precooled tubes containing $500 \mathrm{IU}$ of heparin. Free L-carnitine was determined by radioenzymatic assay ( $\mathrm{SD}=0.8 \mu \mathrm{mol} / \mathrm{liter})$ and total L-carnitine, after hydrolysis by $0.1 \mathrm{M}$ potassium hydroxide and neutralization with $0.5 \mathrm{M} \mathrm{N}$-[2-hydroxyethyl]piperazine- $\mathrm{N}^{\prime}$ [2-ethanesulfonic acid], was determined radioenzymatically $(\mathrm{SD}=1.0 \mu \mathrm{mol} / \mathrm{liter}){ }^{19}$

Scintigraphic measurements: After in vivo labeling with $1,000 \mathrm{MBq}$ of technetium $-99 \mathrm{~m}$, radionuclide angiography was performed in a $35^{\circ}$ to $40^{\circ}$ left anterior oblique projection with an approximate $10^{\circ}$ cranial tilt using a mobile LEM gamma camera (Siemens) equipped with a low-energy, all-purpose collimator, and connected on-line with a mobile MCS/560 nuclear computer system (General Electric). A 20\% window was set around the $140 \mathrm{KeV}$ gamma peak and data were collected in a $64 \times 64$ matrix using a $1.5 \times$ zoom. Framing intervals were calculated to produce 16 frames/cycle. Cardiac cycles, with a cycle length that differed $>10 \%$ from the average cycle length recorded just before acquisition, were automatically excluded from analysis. Imaging lasted 8 minutes at baseline and 4 minutes during pacing and after pacing. Data analysis was performed with a Sophy $\mathrm{P}$ computer (Sopha Medical) using the methods described by Magorien et al. ${ }^{20}$ The following variables were determined: left ventricular ejection fraction (\%), wall motion changes ( $\geq 5 \%$ points change in 9 sectorial ejection fractions), time to peak filling and ejection rate ( $\mathrm{ms})$, and peak ejection and filling rate $\left(\mathrm{sec}^{-1}\right)$.

Drug administration: Patients received either LPC $(15 \mathrm{mg} / \mathrm{kg})$ or its vehicle $(15 \mathrm{mg} / \mathrm{kg}$ mannitol and 19.5 $\mathrm{mg} / \mathrm{kg}$ sodium anhydrous in $0.25 \mathrm{mg} / \mathrm{kg}$ distilled water) over a 5-minute period in a double-blind, randomized fashion.

Study protocol: After instrumentation, a stabilization period of $\geq 20$ minutes was allowed to achieve a minimal interval of 45 minutes between coronary angiography and the study. Multiple control determinations of all hemodynamic variables were then performed to ensure stable baseline values. Next, the first atrial pacing stress test (APST I) was performed, with increments in heart rate of 10 beats $/ 2$ minutes, until angina, atrioventricular block, or a maximal heart rate of 170 beats/min was reached. Forty-five minutes after APST I, after reassessing hemodynamic, scintigraphic, and metabolic variables, patients received either LPC or vehicle. Twenty minutes after the onset of drug infusion, a second atrial pacing stress test (APST II), identical to APST I, was performed. During both tests, hemodynamic variables, lactate, and oxygen were determined at baseline, maximal pacing, and at 15 seconds, 1 , and 10 minutes after pacing. Hypoxanthine levels were determined at control, maximal pacing, and 1 minute after pacing. Arterial carnitine levels were determined before 
and 5,15 , and 45 minutes after the start of the drug infusion.

Data analysis: Data are presented as mean \pm SEM. The statistical analysis consisted of a $t$ test for paired observations and an analysis of variance to differentiate between group differences at the respective time points. A 2 -tailed $p$ value $<0.05$ was considered a significant difference.

\section{RESULTS}

LPC was administered to 15 patients and placebo to 16 patients. Baseline clinical and demographic data are listed in Table I. Both groups were comparable as to age, sex, number of coronary lesions, and left ventricular function. Old myocardial infarctions were present in 13 patients in the LPC group versus 7 in the placebo group $(\mathrm{p}<0.05)$.

Hemodynamic and electrocardiographic changes during pacing: Baseline systemic and coronary hemodynamic variables were comparable in both groups (Tables II and III). In the placebo group, APST I resulted in myocardial ischemia indicated by ST-segment depression of $-0.15 \pm 0.03 \mathrm{mV}$, and an increase in left ventricular end-diastolic pressure from $14 \pm 1$ (baseline) to $21 \pm 2 \mathrm{~mm} \mathrm{Hg}$ immediately after pacing (Figure 1). All parameters returned to baseline values between 5 and 10 minutes after pacing. During APST II, baseline values and changes in hemodynamic and electrocardiographic parameters were similar to those observed during APST I in placebo-treated patients.

In the LPC group, changes during and after APST I were similar to those in the placebo patients, except for cardiac index, which was still significantly reduced in the LPC group 30 minutes after pacing. Hemodynamic changes were comparable during both pacing tests. In contrast to placebo, LPC reduced left ventricular end-diastolic pressure after pacing by $50 \%$ (Figure 1) and resulted in a moderate but significant reduction in ST-segment depression during APST II, whereas the decrease in cardiac index after APST I was prevented after APST II (all $\mathrm{p}<0.05$, APST II vs I).

Metabolic changes: At baseline, myocardial lactate and hypoxanthine extraction values were comparable in both groups (Table III). In the placebo group, a significant but reproducible cardiac release of both metabolites was observed. During APST I, similar changes occurred in the LPC group. At the start of APST II, 15 minutes after LPC administration, myocardial lactate extraction had increased by $24 \%$. Whereas myocardial lactate production was comparable during both tests in LPC, the change from hypoxanthine uptake to release was significantly less during APST II.

Scintigraphic determinations: At basclinc, all variables were comparable in both groups (Table IV). Also, changes in peak ejection and filling rate during APST I were comparable in both groups, and during both tests in the placebo group. In the latter, left ventricular ejection fraction did not change throughout the study. In contrast, it increased by $18 \%$ during APST II after LPC (p $<0.05$ ), together with a significant wall motion score improvement in all but 2 patients. Moreover, and in contrast to the placebo group, LPC improved recovery of myocardial function after pacing with a $21 \%$ increase in peak ejection and peak filling rate and a reduction in time to peak filling ( $-42 \mathrm{~ms}) 10$ minutes after pacing compared with results after APST I ( $p<0.05)$.

Camitine plasma levels: The baseline plasma levels of free and total carnitine were similar in placebo (35 \pm 1.7 and $46 \pm 1.6 \mu \mathrm{mol} /$ liter, respectively) and LPC (36 \pm 1.5 and $47 \pm 1.7 \mu \mathrm{mol} /$ liter, respectively) groups. In the placebo group, arterial levels of total and free carnitine remained unaltered throughout the study. In the treated group, the plasma level of total carnitine increased 15-fold immediately after the infusion of 15 $\mathrm{mg} / \mathrm{kg}$ of LPC, but subsequently decreased to 5 times the baseline level 10 minutes after pacing, approximately 40 minutes after drug administration (Figure 2). Free carnitine levels increased four- to fivefold, and decreased to $92 \pm 6 \mu \mathrm{mol} / \mathrm{liter}, 2.5$ times baseline levels at the end of the study.

Adverse effects: None of the patients experienced any adverse effects.

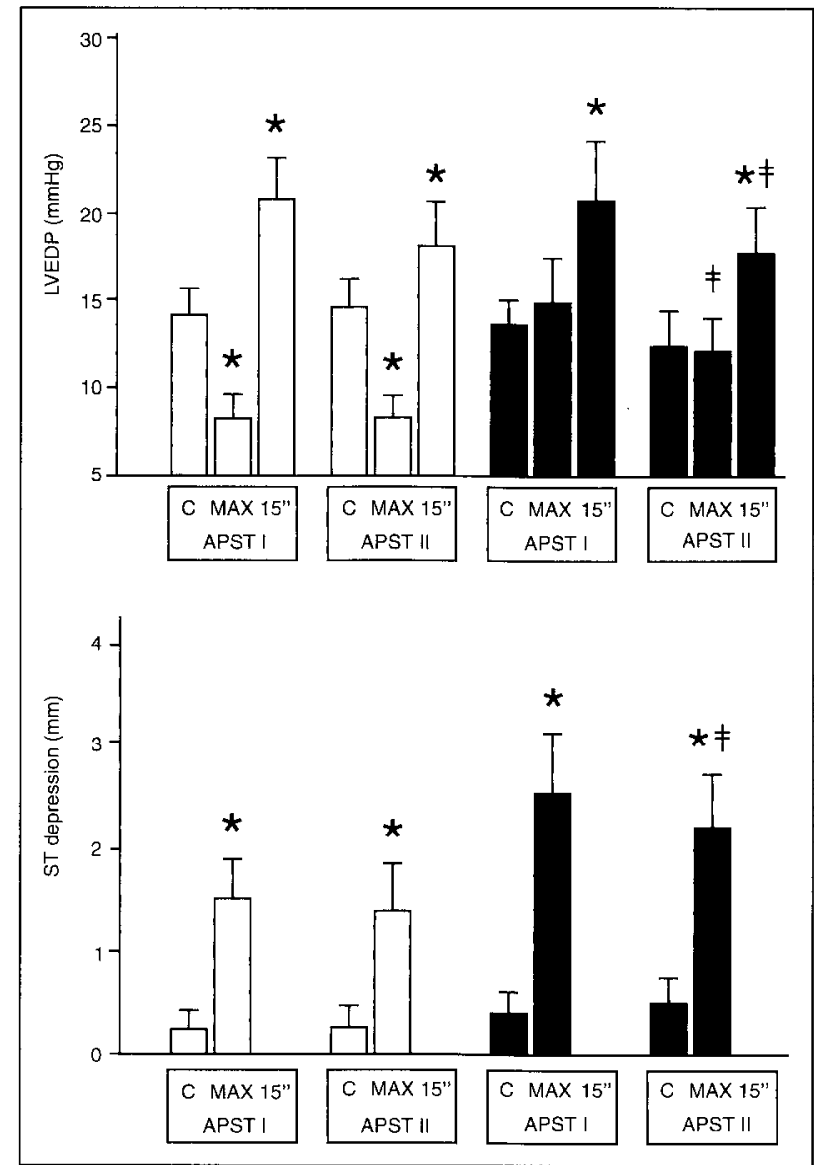

FIGURE 1. Changes in left ventricular end-diastolic pressure (LVEDP) and ST-segment depression during the atrial pacing stress test before (APST I) and after (APST II) placebo (open bars) or L-propionylcarnitine (black bars) administration. L-propionylcarnitine reduces myocardial ischemia as seen by a $45 \%$ reduction in left ventricular end-diastolic pressure immediately after pacing and a $10 \%$ reduction in ST-segment depression during pacing. Values are expressed as mean \pm SEM. *p <0.05 versus control; $\neq p<0.05$, changes during APST I versus changes during APST $\boldsymbol{H}$. $\mathrm{C}=$ control; $M=$ maximal pacing; 15" = 15 seconds after pacing. 

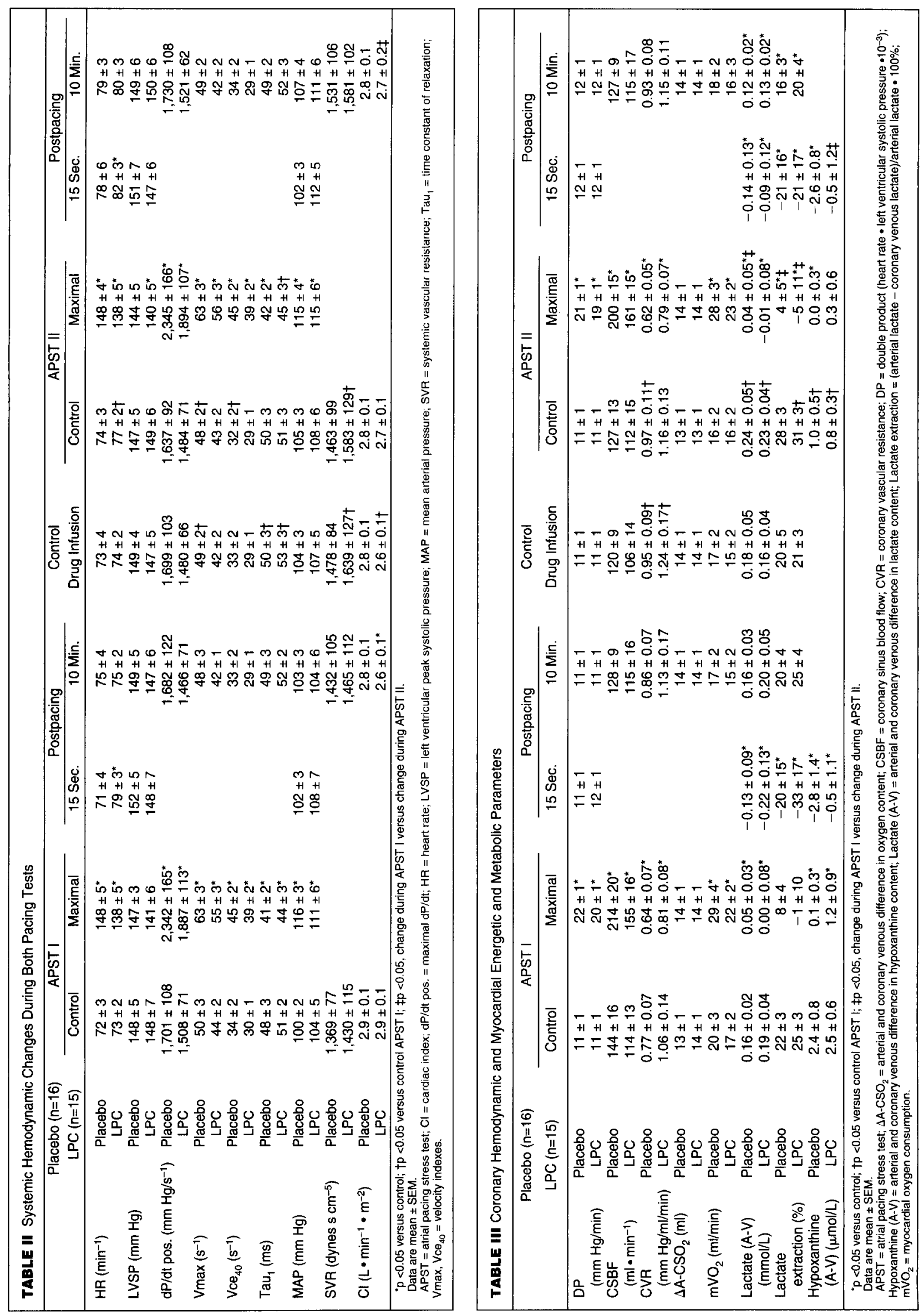


\begin{tabular}{|c|c|c|c|c|c|c|c|c|}
\hline & \multirow{2}{*}{$\begin{array}{c}\text { Placebo }(n=16) \\
\operatorname{LPC}(n=15)\end{array}$} & \multicolumn{2}{|c|}{ APST I } & \multirow{2}{*}{$\begin{array}{l}\text { Postpacing } \\
\text { (10 min) }\end{array}$} & \multirow{2}{*}{$\begin{array}{c}\text { Control } \\
\text { Drug Infusion }\end{array}$} & \multicolumn{2}{|c|}{ APST II } & \multirow{2}{*}{$\begin{array}{l}\text { Postpacing } \\
\text { (10 min) }\end{array}$} \\
\hline & & Control & Maximal & & & Control & Maximal & \\
\hline GEF & $\begin{array}{l}\text { Placebo } \\
\text { LPC }\end{array}$ & $\begin{array}{l}50 \pm 3 \\
43 \pm 4\end{array}$ & $\begin{array}{l}48 \pm 5 \\
43 \pm 4\end{array}$ & $\begin{array}{l}49 \pm 4 \\
39 \pm 3\end{array}$ & $\begin{array}{l}49 \pm 4 \\
39 \pm 3 \dagger\end{array}$ & $\begin{array}{l}47 \pm 4 \\
38 \pm 4\end{array}$ & $\begin{array}{l}50 \pm 3 \\
45 \pm 4 \ddagger\end{array}$ & $\begin{array}{l}48 \pm 4 \\
39 \pm 4\end{array}$ \\
\hline TPE & $\begin{array}{l}\text { Placebo } \\
\text { LPC }\end{array}$ & $\begin{array}{l}123 \pm 12 \\
157 \pm 23\end{array}$ & $\begin{array}{l}109 \pm 10 \\
111 \pm 11\end{array}$ & $\begin{array}{l}128 \pm 16 \\
139 \pm 15\end{array}$ & $\begin{array}{l}139 \pm 15 \\
138 \pm 17\end{array}$ & $\begin{array}{l}131 \pm 12 \\
150 \pm 15\end{array}$ & $\begin{array}{l}111 \pm 18^{*} \\
114 \pm 13\end{array}$ & $\begin{array}{l}136 \pm 16 \\
167 \pm 12\end{array}$ \\
\hline PER & $\begin{array}{l}\text { Placebo } \\
\text { LPC }\end{array}$ & $\begin{array}{l}2.47 \pm 0.22 \\
2.05 \pm 0.18\end{array}$ & $\begin{array}{l}4.04 \pm 0.43^{\star} \\
3.64 \pm 0.39^{\star}\end{array}$ & $\begin{array}{l}2.46 \pm 0.29 \\
1.85 \pm 0.13\end{array}$ & $\begin{array}{l}2.33 \pm 0.23 \\
1.84 \pm 0.14\end{array}$ & $\begin{array}{l}2.27 \pm 0.25 \\
1.83 \pm 0.18\end{array}$ & $\begin{array}{l}4.20 \pm 0.31^{\star} \\
3.88 \pm 0.38^{\star}\end{array}$ & $\begin{array}{l}2.58 \pm 0.30 \\
2.19 \pm 0.20^{\star} \ddagger\end{array}$ \\
\hline TPF & $\begin{array}{l}\text { Placebo } \\
\text { LPC }\end{array}$ & $\begin{array}{l}498 \pm 12 \\
504 \pm 12\end{array}$ & $\begin{array}{l}286 \pm 16^{\star} \\
330 \pm 15^{\star}\end{array}$ & $\begin{array}{l}509 \pm 14 \\
522 \pm 13\end{array}$ & $\begin{array}{l}519 \pm 13 \dagger \\
528 \pm 13 t\end{array}$ & $\begin{array}{l}503 \pm 11 \\
521 \pm 14\end{array}$ & $\begin{array}{l}308 \pm 13^{*} \\
313 \pm 14^{\star}\end{array}$ & $\begin{array}{l}500 \pm 15 \\
497 \pm 16^{\star} \ddagger\end{array}$ \\
\hline PFR & $\begin{array}{l}\text { Placebo } \\
\text { LPC }\end{array}$ & $\begin{array}{l}2.22 \pm 0.21 \\
1.55 \pm 0.16\end{array}$ & $\begin{array}{l}3.49 \pm 0.43^{\star} \\
3.10 \pm 0.46^{*}\end{array}$ & $\begin{array}{l}2.14 \pm 0.19 \\
1.44 \pm 0.14\end{array}$ & $\begin{array}{l}2.05 \pm 0.17 \\
1.30 \pm 0.15 \dagger\end{array}$ & $\begin{array}{l}2.00 \pm 0.22 \\
1.26 \pm 0.13 \dagger\end{array}$ & $\begin{array}{l}4.05 \pm 0.43^{\star} \\
2.87 \pm 0.45^{\star}\end{array}$ & $\begin{array}{l}2.13 \pm 0.20 \\
1.53 \pm 0.15^{\star} \ddagger\end{array}$ \\
\hline
\end{tabular}

\section{Discussion}

In the present study, the potential of LPC to reduce myocardial ischemia following intravenous administration was evaluated in a double-blind, placebo-controlled fashion in patients with coronary artery disease. Whereas the anti-ischemic effects of LPC were already present during pacing, they were most pronounced in the immediate and late postpacing period. Immediately after pacing with LPC, the increase in left ventricular filling pressures was significantly reduced, indicating better preservation of compliance, as compared with results after APST I. In addition, LPC improved scintigraphic measures of contractility and relaxation and prevented the reduction in cardiac output observed after the first untreated pacing test.

So far, several animal studies have reported the ability of LPC to improve mechanical recovery after myocardial ischemia. ${ }^{13}, 15.16 .21 .22$ The present study indicates that LPC may have similar beneficial effects during acute myocardial ischemia and the early recovery phase in humans.

Antifischemic properties of L-propionylcamitineunderlying mechanisms: In the present study, LPC did not affect myocardial ischemia by modulating the myocardial oxygen supply-demand ratio. In anesthetized dogs, $200 \mathrm{mg} / \mathrm{kg}$ of intravenous LPC results in coronary and peripheral vasodilation. ${ }^{23}$ Moreover, in pigs, 50 $\mathrm{mg} / \mathrm{kg}$ of LPC improves myocardial blood flow during reperfusion after 60 minutes of ischemia. ${ }^{16}$ In a previous study, we were unable to observe any acute vasodilating effects of $15 \mathrm{mg} / \mathrm{kg}$ of LPC. ${ }^{24}$ This difference in results between animal and human data may relate to different dosages, a different model of ischemia and reperfusion, and the inability to measure regional coronary flow changes in our study. However, the complete absence of any coronary vasodilating effect of LPC in our study and the absence of changes in myocardial oxygen consumption make a drug-induced improvement in myocardial oxygen supply unlikely. Also, LPC did not affect the rate-pressure product or myocardial contractility during pacing, which indicates that the compound does not interfere with myocardial oxygen demand. Moreover, an increase in citric acid cycle activity should be accompanied by an increase in myocardial oxygen consumption. Although this may be true in the regional ischemic area, an overall metabolic effect is less likely.

Effects of L-propionylcarnitine during the early recovery phase: 'Taken together, the anti-ischemic effects of LPC were moderate during pacing-induced stress, but, in contrast, more prominent during the recovery phase after pacing. As such, our findings agree with observations from animal ischemia-reperfusion studies. ${ }^{13,15}$ In the present study, both systolic and diastolic cardiac function and cardiac output were significantly enhanced during the first 10 minutes of recovery after pacing following LPC. This improvement was not mediated by changes in pre- and afterload or heart rate. More likely, enhanced metabolic recovery and increased myocardial energy stores are involved. In animal ischemia-reperfusion experiments, LPC increases high-energy phosphate concentrations and stimulates fatty acid oxidation during the reperfusion period. ${ }^{25.26}$ Moreover, through modulation of the activity of adenine nucleotide translocase, carnitine is likely to promote adenosine triphosphate transfer from the mitochondrium to the contractile protein site. Finally, the anaplerotic mechanism

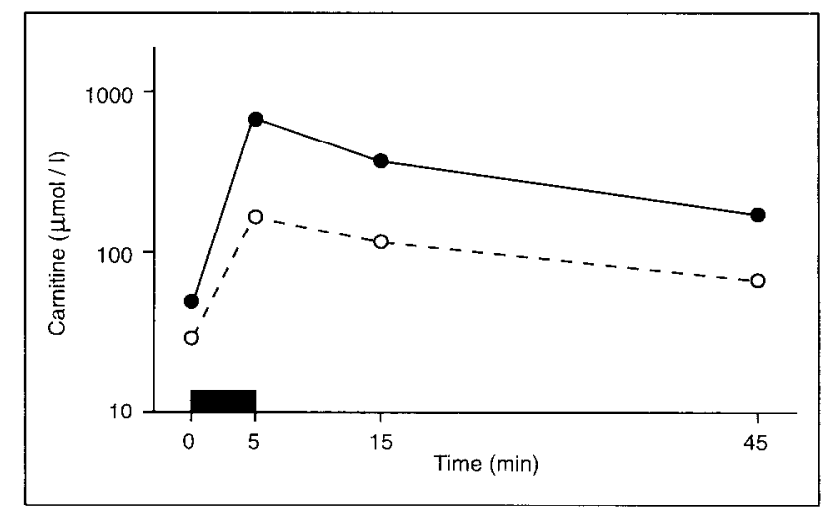

FIGURE 2. Arterial levels of total (closed circles) and free (open circles) carnitine before and after infusion of $15 \mathrm{mg} / \mathrm{kg}$ of L-propionylcarnitine (black bar). Both total and free carnitine plasma levels increased quickly after intravenous administration after which the total carnitine plasma level decreased more rapidly than the free camitine plasma level. Values are expressed as mean \pm SEM. 
of LPC whereby propionyl-CoA is converted to succinyl-CoA, subsequently improving the citric acid flux, may be more effective during reperfusion and recovery, when oxygen is again available and the electron transport chain is free to run.

Cilnical Implications: Our study indicates that LPC acutely reduces myocardial ischemia and improves cardiac function in the recovery period following a short period of ischemia, a modulation that is most likely mediated through its metabolic properties. This alternative mode of action and the absence of any untoward effects suggest a role for LPC in modulating the functional consequences of acute myocardial ischemia and reperfusion.

1. Shug $A L$, Shrago E. A proposed mechanism for fatty acid effects on energy metabolism of the heart. $J$ Lab Clin Med 1973;81:214-218.

2. Shug A, Shargo E, Bittar N, Folts JD, Koke JR, Long chain fatty acyl CoA inhibition of adenine nucleotide in the ischemic myocardium. Am J Physiol 1975 228:689-692.

3. Uziel G, Garavaglia B, Di Donato S. Carnitine stimulation of pyruvate dehydrogenase complex (PDHC) in isolated human skeletal muscle mitochondria. Muscle \& Nerve 1988;11:720-724.

4. Bremer J. Camitine-metabolism and functions. Phys Rev 1983;63:1420-1480.

5. Bieber LL. Carnitine. Ann Rev Biochem 1988;57:261-283.

6. Shug AL, Thomsen JH, Folts JD, Bittar N, Klein MI, Koke JR, Huth PJ. Changes in tissue levels of carnitine and other metabolites during myocardial ischemia and anoxia. Arch Biochem Biophys 1978;187:25-33.

7. Spagnoli LG, Corsi M, Villashi S, Palmieri G, Maccari F. Myocardial carnitine deficiency in acute myocardial infarction. Lancet 1982;1:1419-1420.

8. Liedtke AJ, Nellis SH, Whitesell F. Effects of L-carnitine isomers on fatty acid metabolism in ischemic swine hearts. Circ Res 1981;48:859-866.

9. Folts JD, Shug AL, Koke JR, Bittar N. Protection of the ischemic dog myocardium with carnitine. Am J Cardiol 1978;41:1209-1214.

10. Ferrari $R$, Cucchini $F$, Visioli $O$. The metabolic effects of $L$-camitine in angina pectoris. Intern J Cardiol 1984;5:213-216.

11. Cherchi A, Lai C, Angelino F, Trucco G, Caponnetto S, Mereto PE, Rosolen G, Manzoli U, Schiavoni R, Reale A, Romeo F, Rizzon P, Sorgente L, Strano A, Novo S, Immordino R. Effects of L-camitine on exercise tolerance in chronic stable angina: a multicenter, double-blind, randomized, placeho controlled crossover study. Clin Pharm Ther Tox 1985;23:569-572.
12. Siliprandi N, Di Lisa F, Pivetta A, Miotto G, Siliprandi D. Transport and func tion of L-carmitine and L-propionylcarnitine: relevance to some cardiomyopathies and cardiac ischemia 2 Kardiol 1987.76(suppl 5):34-40.

13. Paulson DJ, Traxler J, Schmidt M, Noonan J, Shug AL. Protection of the ischaemic myocardium by L-propionylcarnitine: effects on the recovery of cardiac output after ischaemia and reperfusion, carnitine transport, and fatty acid oxidation. Cardiovasc Res 1986;20:536-541.

14. Di Lisa F, Menabó R, Siliprandi N. L-propionyl-carnitine protection in ischemic rat heart. Mol Cell Biochem 1989;88:169-173.

15. Liedtkc AJ, DeMaison L, Nellis SII. Effects of L-propionylcarnitine on mechanical recovery during reflow in intact hearts. Am J Physiol 1988;255:H169-H176. 16. Sassen LMA, Bezstarosti K, Van der Giessen WJ, Lamers JMJ, Verdouw PD. L-propionylcarnitine increases post-ischemic blood flow but does not affect recovery of the energy charge. Am J Physiol 1991;261:H172-H180.

17. Remme WJ, Krauss XH, Van Hoogenhuyze DCA, Kruijssen HACM. Hemodynamic tolerability and anti-ischemic efficacy of high dose intravenous diltiazem in patients with normal versus impaired ventricular function. $J \mathrm{Am}$ Coll Cardiol 1993;21:709-720.

18. Remme WJ, Van den Berg R, Mantel M, Cox PH, Van Hoogenhuyze DCA Krauss XH, Storm CJ, Kruijssen HACM. Temporal relation of changes in regional coronary flow and myocardial lactate and nucleoside metabolism during pacing-induced ischemia. Am J Cardiol 1986;58:1188-1194.

19. Lamers JMJ, De Jong-Stinis JT, Verdouw PD, Hülsmann WC. On the possible role of long chain fatty acyl carnitine accumulation in producing functional and calcium permeability changes in membranes during myocardial ischaemia. Cardiovasc Res 1987;21:313-322.

20. Magorien DJ, Shaffer PH, Bush CH, Magorien RD, Kolibash AJ, Unverferth DV, Bashore TM. Hemodynamic correlates for timing intervals, ejection rate and filling rate derived from radionuclide angiographic volume curve. Am J Cardiol 1984:53:567-571.

21. Regitz V, Paulson DJ, Noonan J, Fleck E, Shug AL. Protection of ischemic myocardium by propionylcamitine taurine amide. Comparison with other carnitine derivatives. Z Kardiol 1987;76(suppl 5):52-58.

22. Ferrari R, Ceconi C, Curello S, Pasini E, Visioli O. Protective effect of L-propionyicarnitine against ischaemia and reperfusion-damage. Mol Cell Biochem 1989 88:161-168

23. Cevese A, Schena F, Cerutti G. Short-term hemodynamic effects of intravenou propionyl-L-camitine in anesthetized dogs. Cardiovasc Drug Ther 1991:5:45-56. 24. Bartels GL, Remme WJ, Pillay M, Schönfeld DHW, Cox PH, Kruijssen HACM Knufman NMJ. Acute improvement of cardiac function with intravenous L-propionylcarnitine in man. $J$ Cardiovasc Pharmacol 1992;20:157-164.

25. Ferrari R, Ceconi C, Cargnoni A, Pasini E, Boffa GM, Curello S, Visioli O. The effect of L-propionylcarnitine on the ischemic and reperfused intact myocardium and on their derived mitochondria. Cardiovasc Drugs Ther 1991;5:57-66. 28. Shug A, Paulson D, Subramanian R, Regitz V. Protective effects of L-propionylcamitine during ischemia and reperfusion. Cardiovass Drugs Ther 1991; 5:77-84 